\title{
Small bowel cancer diagnosis: role of nuclear magnetic resonance
}

\author{
Alessandro Morotti, ${ }^{1,2}$ Dario Gned, ${ }^{3}$ Leonardo Di Martino, ${ }^{2}$ Claudia Vaccheris, ${ }^{2}$ Salvatore Lia, ${ }^{2}$ Ubaldo Familiari, ${ }^{4}$ \\ Andrea Veltri, ${ }^{3}$ Angelo Guerrasio ${ }^{1,2}$ \\ ${ }^{1}$ Department of Clinical and Biological Sciences, University of Torino; ${ }^{2}$ Division of Internal Medicine, San Luigi Hospital, \\ Orbassano (TO); ${ }^{3}$ Department of Diagnostic Imaging, San Luigi Gonzaga Hospital, University of Torino; ${ }^{4}$ Division of Pathology, \\ San Luigi Hospital, Torino, Italy
}

\begin{abstract}
The diagnosis of small intestine tumors is challenging. Even in the era of modern medicine, standard approaches including echography, computed tomography-scan and conventional endoscopy are unable to reveal small bowel lesions. Video-capsule has substantially improved the evaluation of small bowel; however this procedure cannot be proposed to all patients and in particular to those experiencing intestine sub-occlusion. Nuclear magnetic resonance (NMR) of the abdomen is an additional diagnostic approach that offers high sensitivity in the identification of small bowel lesions. Here, we describe a case of small bowel neoplasia identified with NMR of the abdomen.
\end{abstract}

\section{Introduction}

Small intestine tumors are rare, with an incidence of less than 1 case per 100,000/year and accounting for less than $0.5 \%$ of all cancers. ${ }^{1}$ However, in almost $80 \%$ of the cases small bowel tumors are malignant. ${ }^{2,3}$ Adenocarcinomas comprise $35-50 \%$ of all tumors, carcinoid

Correspondence: Alessandro Morotti, Department of Clinical and Biological Sciences, regione Gonzole 10, 10043 Orbassano (TO), Italy.

E-mail: alessandro.morotti@unito.it

Key words: Nuclear magnetic resonance; small bowel cancer; video-capsule.

Acknowledgments: we thank all the members of the Internal Medicine Division, San Luigi Hospital, Italy, for their help and discussions.

Contributions: AM conducted the description of the case report; DG, AV provided and discussed NMR and CT-scan analyses; LDM, CV, SL managed the patient; UF provided pathology analysis; AG reviewed the manuscript and the clinical assessment of the patient.

Conflict of interest: the authors have no conflict of interest to declare.

Received for publication: 3 June 2015.

Revision received: 21 July 2015.

Accepted for publication: 28 July 2015.

This work is licensed under a Creative Commons Attribution NonCommercial 4.0 License (CC BY-NC 4.0).

CCopyright A. Morotti et al., 2016

Licensee PAGEPress, Italy

Italian Journal of Medicine 2016; 10:134-136

doi:10.4081/itjm.2015.610 tumors $20-40 \%$, lymphomas $15 \%$ and the remaining is characterized by sarcomas. ${ }^{4}$ Generally, adenocarcinomas are located in the duodenum, while lymphomas and carcinoid tumors are frequently in the ileum. Benign tumors are generally stromal tumor and adenomas. Finally, cancers from other organs may infiltrate peritoneum and small bowel in metastatic diseases. Small bowel tumors did not have a recurrent clinical presentation and could be associated with abdominal pain, unspecific gastrointestinal symptoms or can exhibit symptoms/signs due to the secretion of different hormones. ${ }^{3}$ The diagnosis of small bowel tumor is really challenging even in the modern medicine when novel approaches such as video capsule endoscopy and nuclear magnetic resonance (NMR) are available. ${ }^{5-12}$ Here, we report the diagnosis of small bowel cancer with NMR in a patient presenting with intestine sub-occlusion.

\section{Case Report}

A male patient was admitted to our division of Internal Medicine because of abdominal pain, weight loss and intestinal sub-occlusion. Both abdomen echography and computed tomography-scan (data not shown) did not reveal any significant pathological signs. Due to the persistence of the symptoms, an abdomen NMR was performed. As shown in Figure 1A and $\mathrm{B}, \mathrm{NMR}$ revealed that a portion of the small bowel was characterized by the swelling of the bowel wall. A laparoscopic surgical evaluation was performed confirming the presence of small bowel stenosis. This small intestine segment was therefore surgical removed. At the pathological examination, this portion of the bowel revealed an infiltration of the wall by an adenocarcinoma (Figure 1C). Moreover, infiltration of the peritoneum was also observed (Figure 1D). 


\section{Discussion and Conclusions}

This case report highlights how complex is the diagnosis of small bowel cancer. In particular, the management of patients with intestine sub-occlusion is indeed challenging. Both video-capsule endoscopy and NMR have been referred as powerful strategies to achieve, or to highly suspect, a diagnosis of small bowel cancer. The major limitation of video-capsule endoscopy relies on the fact that patients need to be reasonably fit for this investigation and should not display a sub-occlusive condition. Furthermore, videocapsule endoscopy is not available in all hospitals and requires long diagnostic times. On the contrary, NMR is a more accessible diagnostic procedure and is more cost-effective than capsule endoscopy. However, the great advantage of NMR vs video-capsule is that the NMR can be further implemented by novel additional techniques. In particular, while T2-weighted sequences (with and without fat saturation) and T1-weighted fat saturated sequences remains the standard NMR diagnostic approach for the bowel evaluation, new NMR applications are able to provide additional insights, allowing to obtain a more reliable diagnosis. ${ }^{13}$ Diffusionweighted imaging or contrast-enhanced dynamic sequences should indeed be included in the NMR flowchart to study bowel diseases, as extensively described elsewhere. ${ }^{13}$ Finally, hybrid positron emission tomography/nuclear magnetic resonance (PET/NMR) imaging approaches are under evaluation in several fields of oncology, ${ }^{14,15}$ allowing to integrate morphological analyses (NMR) with functional studies (PET). Therefore, in the next future, clinicians should have a comprehensive, reasonable cost-effective and clinically safe approach to identify the challenging small bowel cancers. Beside NMR implementations, this case re-
A

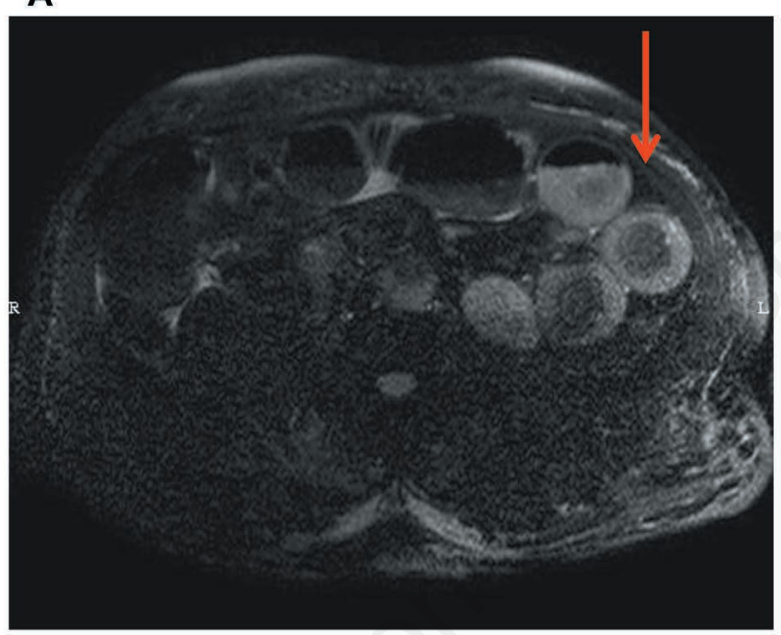

C

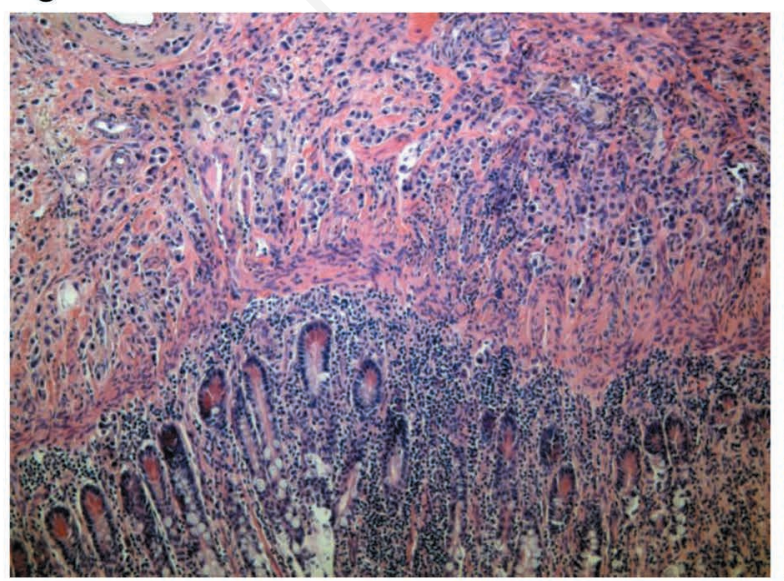

B

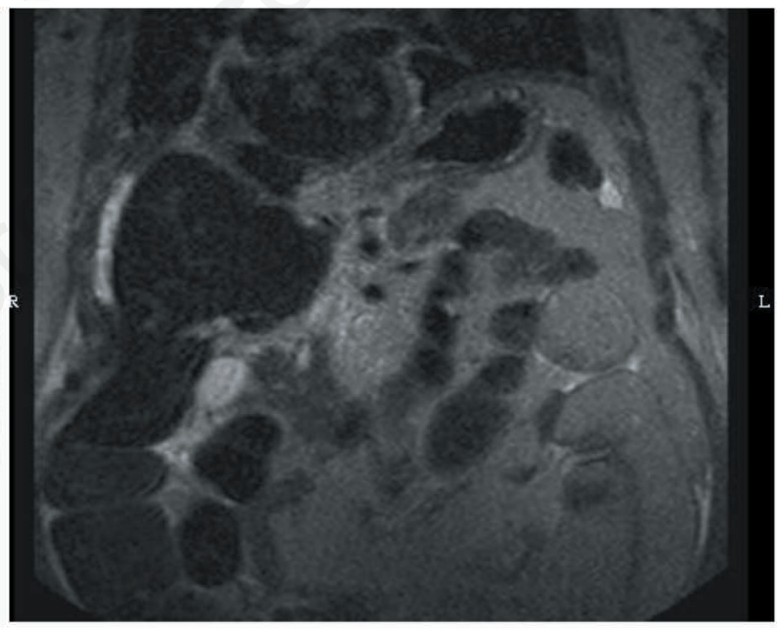

D

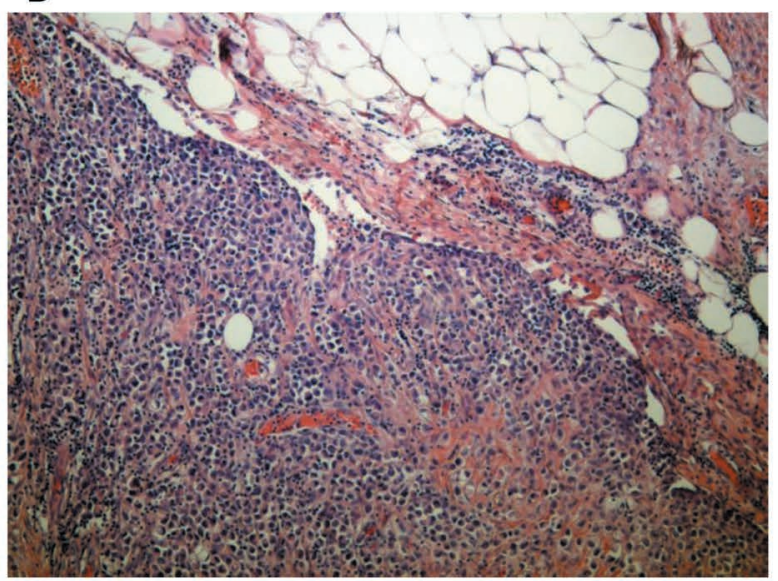

Figure 1. Nuclear magnetic resonance (NMR) evidence of small bowel neoplasia. A) and B) NMR images of the patient abdomen; C) hematoxylin and eosin stain of a portion of small intestine with the evidence of adenocarcinoma infiltration; D) hematoxylin and eosin stain showing infiltration at the peritoneum side of the small intestine. 
port teaches that currently NMR should be considered as an essential procedure in the diagnostic flow-chart of patient with suspected small bowel neoplasia.

\section{References}

1. Pan SY, Morrison H. Epidemiology of cancer of the small intestine. World J Gastrointest Oncol 2011;3:33-42.

2. Aparicio T, Zaanan A, Svrcek M, et al. Small bowel adenocarcinoma: epidemiology, risk factors, diagnosis and treatment. Dig Liver Dis Off J Ital Soc Gastroenterol Ital Assoc Study Liver 2014;46:97-104.

3. Raghav K, Overman MJ. Small bowel adenocarcinomas-existing evidence and evolving paradigms. Nat Rev Clin Oncol 2013;10:534-44.

4. Joensuu H, Hohenberger P, Corless CL. Gastrointestinal stromal tumour. Lancet 2013;382:973-83.

5. Hale MF, Sidhu R, McAlindon ME. Capsule endoscopy: current practice and future directions. World J Gastroenterol 2014;20:7752-9.

6. Islam RS, Leighton JA, Pasha SF. Evaluation and management of small-bowel tumors in the era of deep enteroscopy. Gastrointest Endosc 2014;79:732-40.

7. Liu B, Ramalho M, Al Obaidy M, et al. Gastrointestinal imaging-practical magnetic resonance imaging approach. World J Radiol 2014;6:544-66.
8. Soyer P, Boudiaf M, Fishman EK, et al. Imaging of malignant neoplasms of the mesenteric small bowel: new trends and perspectives. Crit Rev Oncol Hematol 2011;80:10-30.

9. Masselli G, Casciani E, Polettini E, et al. Magnetic resonance imaging of small bowel neoplasms. Cancer Imaging Off Publ Int Cancer Imaging Soc 2013;13:92-9.

10. Crusco F, Pugliese F, Maselli A, et al. Malignant smallbowel neoplasms: spectrum of disease on MR imaging. Radiol Med (Torino) 2010;115:1279-91.

11. Anzidei M, Napoli A, Zini C, et al. Malignant tumours of the small intestine: a review of histopathology, multidetector CT and MRI aspects. Br J Radiol 2011;84:677-90.

12. Sidhu R, Sanders DS, Morris AJ, McAlindon ME. Guidelines on small bowel enteroscopy and capsule endoscopy in adults. Gut. 2008;57:125-36.

13. Kinner S, Hahnemann ML, Forsting M, Lauenstein TC. Magnetic resonance imaging of the bowel: today and tomorrow. RöFo Fortschritte Auf Dem Geb Röntgenstrahlen Nukl 2015;187:160-7.

14. Heusch P, Nensa F, Schaarschmidt B, et al. Diagnostic accuracy of whole-body PET/MRI and whole-body $\mathrm{PET} / \mathrm{CT}$ for TNM staging in oncology. Eur J Nucl Med Mol Imaging 2015;42:42-8.

15. Partovi S, Kohan A, Rubbert C, et al. Clinical oncologic applications of PET/MRI: a new horizon. Am J Nucl Med Mol Imaging 2014;4:202-12. 